úrine, but the albumose was again detected in it. The diarrhoea stopped, but the patient sank and died in the early morning of July 6th. The relatives refused to allow sny postmortem examination, declining to permit even the removal of one of the affected ribs.

\section{Examination of the Urine.}

On the day of this examination (July 2nd) the amount of arine passed was $70 \mathrm{oz}$, and the albuminometer registered 2 paits per 1,000 . In reaction it was distinctly alkaline, and in sppearance very turbid. On standing a heavy white deposit sppearance very turbid. On standing a heavy white deposit settled, which on microscopic examination showed abundance
of triple phosphates, like the earlier specimen, embedded in a putty-like material

'To identify the Bence-Jones albumose I proceeded as follows: $80 \mathrm{z}$. of the urine were filtered to remove the phosphatic deposit. The filtrate, which was still turbld, was carefully neutralized and heated. A dense, sticky white precipitate rapidly appeared, which floated to the top; on further heating i h is largely disappeared. To separate any coagulable proteid this s slution was now filtered while boiling. This second filtrate was allowed to oool, and then treated with nitric acid. An immediste precipitste ocerred at the line of junction of the acid with the urine, which disappeared on heating and reappeared on cooling. In this it corresponds to the reaction of proto-albumose (or, as it is usually called now, primary proteose). After removal of this, nitric acid with sodium chloride protuced a further precipitate, which also disappeared on heating and reappeared on cooling. This corresponds to the reaction of secondary proteose.

Millon's reagent gave a white precipitate with this filtrate, which became reddish-brown on bolling.

To separate the Bence-Jones body some of the albumen-free colution was saturated with crystals of ammonium sulphate. The resulting precipitate was filtered off and redissolved by the aidition of water. With the bluret test it gave a violet colour. This substance therefore corresponded in all respects to the Bence-Jones body, for it possessed the solubilities of proteoses while giving a violet colour with the bluret test instead of a rose colour like ordinary proteoses. To this difference of colour Bradshew ${ }^{7}$ attaches no importance. My observation corresponds, however, to that made by Hatchison in Parkes Weber's case. I am constantly $\mathrm{fngaged}$ in working with the various proteids, and I feel confident that that body with the various proteids, and I feel confident that that body
behaves like an ordinary proteld and unlike a proteose to the behaves lik

There is one slight difference between the behaviour of this substance and that of primary or secondary proteoses to heat. The former is' precipitated at about $60^{\circ} \mathrm{C}$., redissolving on further heating, while the latter are soluble at' all temperatures. Moffatt, however, states that pure Bence-Jones proteose dissolved in water is also entirely unaffected by heat. He thlnks that the effect of heal upon it, when dissolved in urine, is probably due to the presence of uric acld.

REMARKS.

It will be seen that this case agrees in all important particulars with the condition first described by BenceJones in 1848, and now known as Kahler's disease, or myelopathic albumosuria. My attention was drawn to the condition as long ago as 1892 by Dr. Sheridan Lea, who had worked under Kühne. It may be remembered that Kübne described the second recorded case, and recalled the almost-forgotten observations of BenceJones.

The disease usually occurs in men in later middle life, and there is often a period of great weakness and diffase pains, like those of chronic rheumatism, belore the tumours can be detected. There is also marked tenderness on pressure over certain points. In all the points my case is typical. The sudden appear ince of the tumours was probably due to barsting of the growth in the marrow through the compact tissue of the bone, as has been ob zerved by Moffatt.

As in Bradshaw's first case, the urine became milky partly through spontaneous deposit of the proteose, but also, no doubt, in part through the abundant phosphatic deposit. Unfortunately, a quantitative estimation of the phosphates was not made, and in its absence it cannot be definitely stated that there was an excess of earthy phosphates in the urine, thongh the large amount of deposit was very suggestive. Excess cf earthy phosphates has, however, bet $n$ noted by Hutchison, and is no doubt the result of the destruction of the bone. An increase of the earthy phosphates in proportion to the phosphates of the alkalies occurs, however, in many wasting diseases, the normal ratio of 1 to 2 becoming as high as 5 to 2 (von Noorden).

As to the significance of the albumosuria, we may conclude with Moffatt" that, "save for a few rare and perhaps doubtful cases, Bence-Jones albumosuria is always associated with disease of the bone marrow." The view that the albumose is alimentary in origin (Magnus-Levy) appears to me to be untenable, for the following reasons:

1. We know now that proteolysis normally proceeds far beyond this stage, the end-products being hexone bases and amino acids.

2 The Bence-Jones albumose is not identical ln i is reactions with the digestive albumoses.

3. Parkes Weber found that considerable alteration of the diet hat no effuct on the amount of proteld excreted, and this I was able to confirm in the present case.

4. The alimentary view fails to explain why marked and persistent albumosuria should only occur in this particular form of malignant disease.

The view advanced by Parkes Weber that the albumose is produced by the changes going on in the bone marrow has more to recommend it. Hutchison and Macleod were able to extract a proteid, giving very similar reactions to the Bence Jones body, from the vertebrae and femur of Parkes Weber's second case, but not from the blood and organs.

In the present case the coexistence of a true albuminuria with hyaline and granular casts obscured the diagnosis for a time. But with a blood pressure of only $120 \mathrm{~mm}$. it was not possible to explain even the earlier symptoms hy reference to chronic interstitial nephritis, and this led to a more careful inquiry.

Death apparent]y resulted from a terminal pneumococcal infection, to which the patient totally failed to react, as shown by the leucopenia and absence of fever. As Parkes Weber stated in his first paper on the subject, pneumonia seems to be the most usual cause of death.

Even though no post-mortem examination could re obtained, the diagnosis seems fairly certain in this cf $\mathbf{B e}$ for no other explanation will account for all the facts, $n$. is there anything in the case inconsistent with such an explanation.

The following refe RECENT BIBLIOGRAPHY.

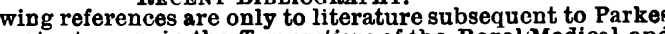
Weber's important paper in the Transactions of the Royal Medical and indebted to Dr. Parkes Weber's rind esess

xlvi, p. 125.
Abrikossoff: Virchow's Arch., 1903, vol. clxxiii, p. 335.

3 Anders and Boston : Lancet, 1903, i, p 93

4 A schoff : Muench. med. Woch., February 13th, 1906, p. 337 .

3 Bertoye: Rev. de Méd., Paris. April and May, Xo9.4 and 5, 1904.

6 Boston : Amer. Journ. Mcd. Sci., April, 1903. p. 658.

7 Bradshaw : BRITISH MEDICAL JOURNAL, 1906, ii, p. 1442.

Bruce, Lund, and Whitcombe : Lancet. 1904, i, p. 1045.

9 Charles and Sanguinetti: BRITISH MEDICAL JOURNAL, 1507,

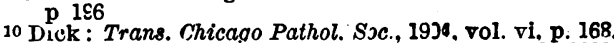

10 Dick: Trans. Chicago Pathol. SJc., 19J4. vol. vi. p. 168.

11 Gluzinski and Reichenstein: Wien. klin. Woch.,

13 Hoffmann: Beiträge zur path. Anat. und Allgem. Pathol, 1903,

vol. XXXv, p. 317.

15 Hueter (abstract) $:$ Muench. med. Woch., A pril 16th, is07, p. 811.

16 Jellinek : Virchow's Arch, 1904, vol. clsxvii, p. 96.

Lindermann : Deut. Arch.f. klin. Med .1904, vol.1xxxi, p. 114

18 Lubarsch : Virchow's Areh. 1903, vol. clxxxiv, p. 213.

19 Menne: Virchow's Arch.. 1906, vol. clxxxii.

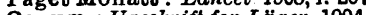

Oenum : Ugeskrift for Läger, 1904. Nos. 15 and 16

.

政 9

Saltyrow: Virchow's Arch., 1903, vol. clxxiit, p. 531.

25 Scheele and Herxheimer: Zettsch.f. klin Med., 1904. vol liv. :6 Simmonds (abstract): Muench. med. Woch., July 17th. $1 \leqslant 06$, p. 1438.

27 Von Verebely: Beiträge zur klin. Chirurg., 1906, vol. xlvili,

28 Voit and Salvendi: Muench med. Woch, July 19th. 1904, p. 1281.

9 Parkes Weber and Blendinger : Journ. Paih. and Bact., January.

1936. p. E9.

. Wien. klin. Woch., 1903, p. 461.

\section{THE EYESIGHT OF TEE POORER CITY CHILDREN.*}

By H. WRIGHT THOMSON, M.D.,

OCULIST TO THE SCHOOL BOARD OF GLASGOW: ASSISTANT SURGFON,

GLASGOW OPBTHALMIC INSTITU

IT is a well-recognized fact that, apart from short-sightedness or other forms of optical defect, the power of observation, as distinguished from mere seelng, is developed to an exceedingly variable degree in different individuals and classes. Also, it is obvious that in determining such variation the influence of training is very considerable. The detective officer going into a room notices much more than the ordlnary individual. They both have the same pictures formed in their eyes, but only the one has a brain * Read at the Second International Congress on School Hygiene, London, August, 1937. 
capable of taking in all, or nearly all, the detalls of the picture in a very short time. The different impressions which two such people leave the room with may be compared to a photograph and a sketch, the one exact to the smallest detail, the other showing only the general effect.

Examples of such differences in trained powers of observation might be multiplied indefinitely, but mention need only be made of the sallor's superiority over the landsman in detecting distant ships or lights, and the countryman's sharpness in picking out from afar off individual persons or animals.

In speaking of such visual qualifications it is usual to refer to them as the result of training the eye, and for ordinary purposes this may be enough. It must be remembered, however, that the eye does not perceive. Pictures are formed in it, but they are interpreted by the brain, and the difference as regards power of observation between two persons each of whom has normal eyes is due not to difference in sharpness of eyesight, but sharpmess of brain power to interpret what is seen equally well by both.

When we think of the adult's visual perspicuity and its apparent relation to training and environment, an important field of inquirg, it seems to me, is suggested for the educationalist. First, can it be shown that children vary in acuteness of visual power according to their environment? Becondly, if they do, can anything be done for them at school?

In attempting to answer these questions I wish to bring forward evidence obtained in my work as oculist to the School Board of Glasgow. During one session I investigated the eyesight of the children above the infant department stage in all the Board's schools. The number of children examined was 52,493, attending 67 schools, situated mostly in working-class districts in all stages of prosperity. It is not necessary here to detail the method of examination adopted further than to state that the first examination was made by the teachers, and that those children whom they found to have defective vision were referred to me for further investigation. Further, I may add that by making control observations I was able to satisfy myself that in deallng with sach large numbers one might quite ignore the personal equation of the teachers as affecting the results.

The result of this testing by the teachers was that 35 per cent. of the children were shown to have defective vision in one or both eyes. I examined these children, and found that many of them, although unable to see well, had nothing apparently wrong with their eyes. They had neither evidences of ocular disease, nor were their eges longsighted, shortsighted, or astigmatic. Moreover, in the cases which I saw subsequently at hospital, their vision could not be improved by the use of glasses. It seemed as though their visual difficulty was entirely functional, and, while the acu teness of vision was in most cases moderately near the normal standard $\left(\frac{6}{12}\right.$ or $\left.\frac{6}{18}\right)$, in not a few the depreciation was extreme $\left.\left(3^{\frac{6}{6}} \text { or } \frac{6}{6}\right)^{6}\right)$. The proportion of the total number of children who were thus functionally defective was 14 per cent., but as different schools had widely different percentages, $:$ I made an analysis of the results with a view to finding any suggestive circumstances associated with their distribution. I constructed a chart* in which the individual schools were arranged according to the percentage of defectives found by the teachers, and in which, also, were indicated by a second line the percentages found defective by me. The space between these two lines gave for any school the percentage of functional defectives--that is, those whom the teachers lound to have defective sight, yet whose eyes I found to be normal. Now, the teachers' line began very high (53 per cent.), and gradually fell to 20 per cent. My line with a few exceptiuns, moved within the limits of 16 and 28 per cent. To put it in another way, the proportion of children whose defective vision could be improved by the wearing of spectacles was nearly the same in all the schools, but the proportion of those who had defective sight, yet did not required spectacles, varied within wide limits. It was a striking fact that the school at the high end of the chart line, with 25 per cent. of its numbers thus functionally defec*For this and other details see report published by the School
Board of Glasgow, 1906. tive was . situated in a poor diatrict in the middle of the city, while the school at the other end with but 3 per cent. functionally defective was right on the city's edge within aight of the open country. And that this was no mere coincidence was indicated by the fact that most of the city schools were at the upper end of the chart line, and the schools of the outskirts at the other. I next arranged the schools in city districts, and compared the gogregate results. The result was the same-the nearer the district to the open country, the smaller the proportion of Its children who were functionally defective. Further, I examined the children of two country schools, the one in a village many of whose adult inhabitants are city bred and city employed; the other in a purely agricultural village. Both were much superior visually to the best of the city schools, and of the two, the agricultural school had the smaller number of children functionally defective. There thus seemed to be clearly indicated a definite relationship between district of residence and visual acuteness, apart from optical defect.

Why should a child who has perfectly good eyes see so much worse if he stays in a street in the middle of the city than if he were a country child, or even a suburban child? It would be very difficult to make a complete reply to this question, because there must be many causal factors, but some of these are demonstrable. The social status is undoubtedly one canse, for the visual standard in slum districts is the lowest, and it is highest in the best-class schools. But the best-class schools are those nearest the edge of the city, and, inasmuch as country school children see best of all, the comparative openness of the best-class school districts probably has something to do with their superior vision. That it is not the whole cause, however, is shown by comparison of city districts equally remote from open country, but of different degrees of prosperity, which shows a decided visual advantage in favour of the better-off children. It may therefore be safely asserted that the poorer a city child's circumstances are, and the more closely built his district is, the less likely is he to have sharp distant vision; but to attempt to apportion to these two conditions their relative causal valnes is hardly possible in the present state of our knowledge. It is true $I$ have found that the poorest country children have excellent distant vision, but it would not be fair to say that that is entirely due to their being accustomed to look long distances, because even the poorest country child is physically very superior to his brother of the slums. His food is usually wholesome, his surroundings more healthful, and his general nutrition is much more satisfactory, and, of course, his eyes and brain share in the general wellbeing.

Again, working-class children who live near the city's edge see better than those who seem to be equally well off, yet stay in densely built parts ; but the very proximity to the country must have some influence on the general health, so we are not entitled to say that the visual euperiority is entirely due to the greater scope for practising distant vision. We must, therefore, leave these two causal factors linked together in our affirmative answer to the question, Can it be shown that children vary in acuteness of visual power according to their environment?

Passing now to the second question suggested in this paper, Can anything be done at school to improve the poorer city child's vision? I think an affirmative answer may again be given. First, attention ought to be paid to the fact that these children are habituated to a short range of vision. They live in closely congested districts; their playground is the street or a small backyard. They rarely have occasion to look any considerable distance, yet up to the age of 7 or 8 a child's eyes are structurally better adapted for distant than for near vision; indeed, peering at close objects involves the eye in an amount of accommodative strain which is apt to produce permanent bad effects.

Now, it is well recognized that children in general should not be called upon to use their eyes much for near objects while at the infant department age. Surely, then, in the case of the poorer city children it is not only imperative that they be not made to strain their eyes poring over minute work, but an effort should be made to train their sharpness of vision for distant objects. Focussing for near objects means the exercise of muscles in and round the eye. Looking at distant objects-provided the eyes be normal, or, if abnormal, fitted with glasses-demands little, if any, 
muscular exercise. The former produces exhaustion and possible permanent harm; the latter may weary the child mentally if continued too long; but the symptoms of this are obvious to the teacher, and no permanent damage is done. Sewing should certainly be abolished as an item of the infant curriculum. Most of the teaching should be done by means of objects, figares, and letters which are large in size, and placed at a distance from the pupils. All writing and drawing by the papils should be on a large scale, and consequently any ruled paper which is used should be as widely spaced as possible. Further, I would deprecate the use of small multi-coloured squares of cardboard, with which I have seen children building up patterns, to merely look at which caused discomfort in the eyes. I am confident that good might be done by the institution of competltive games, which would Involve the use of the -eyes for distanees of $20 \mathrm{ft}$. and over. Objects or pictures could be momentarily displayed to a class, then descriptions asked of what was seen. The complexity of the picture or object would vary according to the ages and progress of the children, also the time of exposure. On such a principle a great variety of games might be arranged and an improvement in two most important attributes-namely, sharpness of distan vision and quickness of observation-would result, which would amply justify the trouble involved.

So much for trying to counteract the visual disability of poorer city children in so far as it results from their habitual limited range of vision. The other causal factor which is suggested by my observations is the general nutrition of the child. This must be largely dependent on the atmosphere in which the child lives and the nature of the food which he receives. Most teachers of experience are decided in the opinion that it is not the amount of food received by the children of the poor which is so much at fault as the nature of it. The same money might be spent so much more judiciously.

I do not wish to deal with the administrative question of how to feed the necessitous poor school children, but I would like to record an observation of the apparent effect of feeding on vision.

There are two kinds of industrial schools in Glasgow. The one is the day industrial school, which is situated in a central part of the city and to which the children go in the mornings from their own homes, and remain till the evenings, receiving their three meals in school. The other is the residential industrial school, which is situated in the country. All these industrlal school children are well and amply fed, and they are drawn from the poorest social stratum. I examined them in the same way as I did the Board School children, and compared the results. I found that while defective eyesight due to physical causes was very common, defective eyesight for which no physical cause could be found-that which I have referred to as functional defect, and which $I$ have found so markedly associated with residence in crowded and poor districtswas much less common in the industrial than in the poorer city schools. This result is all the more striking in that every industrial school child has come from a povertystricken home, but in even the poorest Board school there Is a proportion of well-fed children. Surely it cannot be doubted that the good feeding of the industrial school child and his visual superiority over his social brother fed at home stand in the relationship of cause and effect.

In conclusion, let me recapitulate. The poorer city school children are liable to have functionally defective eyesight-that is, a defect of sight which is not due to any physical abnormality of the eyes, but seems to be due partly to want of training and partly to malnutrition. The effect of the want of training might be, to some extent at least, neutralized by certain modifications of the infant department curriculum at school, notably by abolishing sewing and all forms of work which require close poring over, and by instituting suitable visual exeroise games. The effect of malnutrition might be combated by proper feeding during school life, as I have found it to be in the industrial schools which I investigated.

THE French Minister of Public Instruction has accorded to Miss Alice $H$. Brunton, the daughter of Sir Lauder Brunton, the diploma of Officier de l'Instruction Publique, in recognition of her services to the recent Second International Congress on Hygiene.

\section{SYNERGIC MOVEMENTS OF THE EYELIDS AND MOUTH.}

BY W. M. BEAUMONT, SURGEON TO THE BATH EYE INFIRMARY.

THE accompanying illustration shows the ordinary appearance of a case of congenital ptosis with $\epsilon$ picanthus. The breadth between the inner canthi of the two eyes is very marked, and the flattening of the bridge of the nose is conspicuous. The child is 9 months old, and when the photograph was taken her attention was attracted by some means. In trying to raise. her eyelids her mouth is opened, and it shuts again as soon as she gives up attempting to uge the eyes.

Such cases of mouth and eyes acting in unison are very common, especially in children who have some difficulty in opening the eyes, either from congenital disease or from acquired conditions, such as photophobia. Some years ago I recorded a similar case, ${ }^{1}$ and other allied ones show that under certain circumstances there are asgociated movements of the ocular and oral muscles. This association is no mere pathological curiosity of rare occurrence, for it is to be seen in the ordinary expression of the emotion of surprise by gaping, although it is not, I think, associated with yawning.*

But associated action of eyes and mouth are not confined to the expression of surprise alone, for any

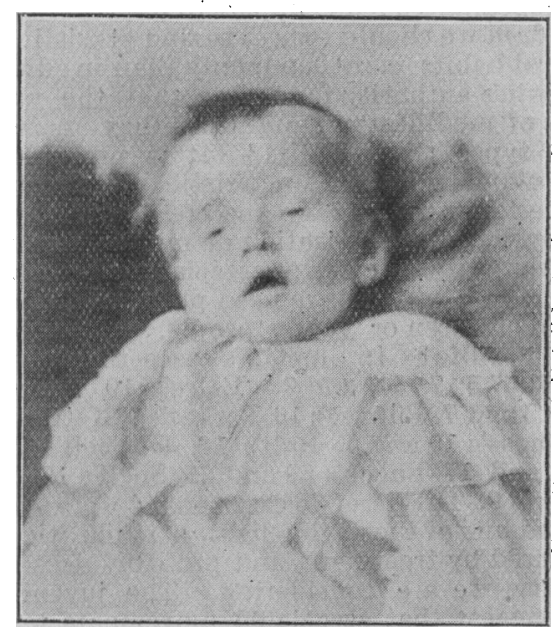

exaggerated attempt to open the eyes would seem to be accompanied by an opening of the month. This is frequently observed by surgeons in children suffering from photophobia, who commonly open their mouths in straining to open the eyes. The tendency of mouth and eyes to open together may be readily tested by putting a finger between one's own teeth and gripping it firmly. If the eyes are now widely opened a relaxation of the grip will be experienced. Or if the mouth be s]ightly opened and then the eyelids are opened to their widest extent, we shall see if we look in a mirror that there is an inclination for the mouth to open still wider.

This assoclation of eyelids and mouth is recognized in the post-operative treatment of cataract, when it is usual for some days not to allow patients food which requires biting.

The tendency for mouth and eyes to act together may be tested conversely to find out whether closing the ey es is associated with closing the mouth. Again, on putting the * The distinction between gaping and yawning would seem to be
that the latter is accompanied by a deep inspiration. and is usually a sign of fatigue, either mental or physical: The dropping jaw of fright is probably a form of temporary paresis akin to relaxation of the sphincters under similar circumstances. A gape is defined in Murray's dictionary as an "open-mouthed stare"; and to gape is to Dryden has the same idea in "Cymon and Iphigenta" "The fool of Nature stood with stupid eyes," ".arwin, in the Expression of Emotions (p. 278. 1872 edition), says this state increases into surprise the are raised to a much greater extent, with the eses and mouth widely open. The raising of the eyebrows is necessary in order that the eyes should be opened quickly and widely : and this movement froduces transverse wrinkles 